\title{
Percutaneous Closure of ASD in a Child with Bilateral Femoral Vein Obstruction: An Unconventional Route
}

\author{
Dr Aditi Gupta MD \\ Fellow in pediatric cardiology \\ Dr Munesh Tomar* \\ Department of pediatric cardiology \& congenital heart diseases, Medanta-The Medicity.Gurgaon, India \\ *Corresponding Author: Dr Munesh Tomar, Department of pediatric cardiology \& congenital heart \\ diseases, Medanta-The Medicity.Gurgaon,India,Email: drmuneshtomar@gmail.com
}

\begin{abstract}
The internal jugular vein is not a typical vascular access used for percutaneous closure of Atrial septal defect. We report the closure of an Atrial Septal Defect in a 5 year old child with bilateral iliac veinobstruction due to thrombosis with a single device using a transjugular venous approach
\end{abstract}

\section{INTRODUCTION}

The transcatheter closure of OstiumSecundum Atrial septal defect (ASD) is a well-established procedure. It is currently considered the procedure of choice due to the good outcomes and low morbidity and mortality. The procedure is routinely performed through the femoral vein approach. However rarely it may not able to deploy the device via femoral route due to obstruction or the interruption of the inferior vena cava. In such cases alternative routes like the transjugular and transhepatic routes are considered.

We report the closure of an Ostium Secundum ASD in a five-year-old boy using a Amplatzer Septal Occluder Device via Trans jugular approach due to bilateral femoral vein obstruction by thrombus.

\section{CASE REPORT}

A 5-year-old boy wasborn at 36 weeks gestation byElective Caesarean Section (in view of Cephalopelvic disproportion) to primigravida mother with birth weight of $2.8 \mathrm{Kg}$. He was admitted in neonatal Intensive care unit at day 8 of life with sepsis and during that time diagnosed with Ostium Secundum ASD and large patent ductus arteriosus (PDA).He had a prolonged stay in Neonatal Intensive Care Unit (21 days) which included baby being on ventilatory support for 5 days. As per the available records, femoral venous access was taken during the intensive care stay. Later he underwent surgical ligation of PDA at 3 months of age .His postoperative period was uneventful. Child had been doing well since then and was under regular follow up for ASD.

He was planned for Elective transcatheter closure of ASD at age of 5 years and child was admitted for same. At the time of admission child was stable, with no syndromic features and had achieved all developmental milestones appropriate for age. Transthoracic echocardio gram done revealed Ostium Secundum ASD of size $10 \mathrm{~mm}$ with left to right shunt, mild tricuspid regurgitation (peak gradient $32 \mathrm{mmHg}$ ), Dilated right atrium and ventricle due to diastolic volume overload with Normal ventricular Function.

After proper counseling and consent of the family, patient was taken up for percutaneous ASD closure under General anesthesia under Transesophageal Echocardiography (TEE) guidance. It was initially planned to take venous accessof 5 French (Fr) sheath in the Right femoral vein for the deployment of device. However, guidewire could not be negotiated into the inferior vena cava. Left Femoral vein access was then tried which was achieved with insertion of $5 \mathrm{~F}$ sheath however there was distal obstruction and terumo wire could not be negotiated into inferior vena cava (IVC). Manual contrast injection was then performed through left femoral vein, and obstruction of bilateral iliac veins was observed with no direct communication of these veins with the inferior 
vena cava. Filling of IVC could be seen via multiple venous collaterals (video 1 ).

\section{Video1: https://youtu.be/ZscEN0pW9tI}

Venous access was then achieved using the right internal jugular vein with a $5 \mathrm{Fr}$ sheath. Heparin at 100 unit per kilogram of body weight was administered intravenously. ASD was first attempted to be negotiated via Multipurpose catheter but was unsuccessful.A 5 Fr Right Judkins catheter with Terumo guidewire was introduced under fluoroscopy. The guidewire was stabilized into the left ventricle instead of the left pulmonary vein due to difficulty in entering pulmonary vein from trans jugular approach. After placement of the catheter in left ventricle, terumo guide wire was exchanged with Amplatzer Extra stiff guide wire. Over extra stiff guide wire, 8FMullin's sheath was taken and Amplatzer septal occluder (St. Jude Medical) device (12 mm) was taken up to the tip of the sheath. Proper precautions were taken to avoid air embolism. Whole assembly was then withdrawn very slowly under TEE guidance. Left atrial disk was released just above the mitral valve to avoid any injury to mitral valve and then right atrial disc was opened across the ASD sequentially under fluoroscopic and transesophageal echocardiographic guidance (video 2).

\section{Video2: https://youtu.be/xQTRrtSn6Z8}

Alignment of left atrial disc was not parallel to atrial septum but as right atrial disk was released, left atrial disk become well aligned to atrial septum and device was seen positioned well across ASD. Transesophageal and Transthoracic echocardiography revealed device in situ with no residual shunts, normal atrio ventricular valve with mild tricuspid valve regurgitation and normal superior and inferior vena cava blood flow. After confirming the above findings on multiple views on TEE and Transthoracic Echocardiography, device was released. Patient was weaned off General Anesthesia and was discharged on next day of procedure after rechecking the device position on Transthoracic Echocardiography. Patientwas discharged on oral antiplatelet (Tablet Ecosprin) and Infective Endocarditis Prophylaxis for 6 months. Patient has been under regular cardiac follow up since then and last follow up done 8 months post procedure revealed ASD Device in situ with no residual shunt, Mild Tricuspid Regurgitation, Normal ventricular Function with Normal PA pressures.

\section{DISCUSSION}

Device closure is the preferred method for managing Atrial Septal defects since the last 40 years. King and Mills first performed the ASD device closure in 1974 (1). The procedure is conventionally performed via the femoral vein approach due to the low incidence of associated complications and easier manipulation of the device compared to other access routes. However in certain situations it is not possible to deploy the device via femoral route like interrupted inferior vena cava, congenital or acquired obstruction due to membrane or thrombus in IVC and continuation of venous flow in form of azygous vein or multiple venous collaterals.

Under such circumstances, alternative routes for catheterization have been reported. In 1995, Sommer and colleagues (2) reported a percutaneous transhepatic approach as an alternative catheterization route in pediatric patients. Since then there have been multiple case reports of closure of ASD via transhepatic approach (3). Major complications of the transhepatic approach include retro- or intraperitoneal bleeding, hemobilia, injury to the gall bladder, portal vein, lung, pleura and liver.

In our case, it was not possible to use the femoral approach due to bilateral iliac venous occlusion. This was a complication most likely due to previous femoral venous access during prolonged ICU stay in neonatal period

On reviewing the literature, we could find only few case reports, mainly in adults, of transjugular approach for percutaneous closure of $\operatorname{ASD}(4,5,6,7,8)$. In pediatric age group we could find only two case reports $(9,10)$

The difficulties associated with the transjugular approach include placing a large sheath in the jugular vein, manipulating the wire and catheter past the defect, and stabilizing the catheter or guidewire prior to deployment of device. Also there is a significant risk of air embolism during the procedure.

Experience in performing the standard procedure and accessing the transjugular vein are mandatory to perform the procedure through the transjugular vein, because the device alignment is reversed compared to the femoral venous approach. Moreover, caution is required, due to the risk of air embolism. Otherwise, the transjugular approach is a good alternative to the femoral venous approach. 


\section{CONCLUSION}

We conclude that the percutaneous transjugular approach for a transcatheter ASD closure is a safe and alternative method when femoral venous access is not possible.

\section{REFERENCES}

[1] King TD, Mills NL. Nonoperative closure of atrial septal defects.Surgery.1974;75: 383-388.

[2] Sommer RJ, Golinko RJ, Mitty HA. Initial experience with percutaneous transhepatic cardiac catheterization in infants and children. Am J Cardiol 1995; 75 (17):1289-91.

[3] Oliveira EC, Pauperio HM, Oliveira BM, da Silva RA, Alves FM, Adjuto GL. Percutaneous closure of atrial septal defect using transhepatic puncture. Arq Bras Cardiol. 2006; 87:193-6.

[4] Papa M, Gaspardone A, Fragasso G, Camesasca C, Conversano A, Tomei F, et al. Jugular approach for percutaneous closure of atrial septal defect. Ital Heart J. 2004;5: 466-9.

[5] Sullebarger JT, Sayad D, Gerber L, Ettedqui J, Jimmo-Waumans S, Alcebo PC. Percutaneous closure of atrial septal defect via transjugular approach with Amplatzer septal occluder after unsuccessful attempt using CardioSEAL device. Catheter CardiovascInterv. 2004; 62: 262-5.

[6] Sader MA, de Moor M, Pomerantsev E, Palacios IF. Percutanous transcatheter patent foramen ovale closure using the right internal jugular venous approach. Catheter Catheter CardiovascInterv. 2003; 60:536-9.

[7] Rao D Seshagiri, A N Patnaik, B Srinivas. Percutaneous closure of atrial septal defect via transjugular approach with Blockaid device in a patient with interrupted inferior vena cava. CardiovascIntervTher 2013 Jan 19; 28(1):63-5. Epub 2012 Jul 19.

[8] Saktheeswaran Mahesh Kumar, Sasidharan Bijulal, Kavassery Mahadevan Krishna moorthy. Percutaneous transjugular device closure of postoperative residual atrial septal defect. J Invasive Cardiol 2013 Apr;25(4):E7880

[9] Ozbarlas N, Kiziltas A, Kucukosmanoglu O, Erdem S. Transjugular approach to device closure of atrial septal defect in a child with heterotaxia and interrupted inferior vena cava. Tex Heart Inst J 2012; 39: 435-7.

[10] Osman Baspinar, Khaleel Ibrahim Al-Hadidy, Mehmet Kervancioglu.Transjugular closure of a two hole atrial septal defect in a childwith iliac vein thrombosis. Ann PediatrCardiol. 2013 Jul;6(2):185-7

[11] Sheridan RL, Weber JM. Mechanical and infectious complications of central venous cannulation in children: Lessons learned from a 10 -year experience placing more than 1000 catheters. J Burn Care Res. 2006; 27:713-8.

Citation: Dr. Aditi Gupta MD, Dr. Munesh Tomar. Percutaneous Closure of ASD in a Child with Bilateral Femoral Vein Obstruction: An Unconventional Route. ARC Journal of Clinical Case Reports. 2017; 3(2):13. doi:dx.doi.org/10.20431/2455-9806.0302001.

Copyright: () 2017 Authors. This is an open-access article distributed under the terms of the Creative Commons Attribution License, which permits unrestricted use, distribution, and reproduction in any medium, provided the original author and source are credited. 